\title{
50 Years of the Korean Geriatrics Society
}

\author{
Hyung Joon Yoo* \\ Department of Endocrine and Metabolism, CM Hospital, Seoul, Korea
}

Corresponding Author:

Hyung Joon Yoo, $\mathrm{MD}, \mathrm{PhD}$

https://orcid.org/0000-0002-7755-9246

Department of Endocrine and

Metabolism, CM Hospital,

13, Youngdungpo-ro 13-gil,

Youngdungpo-gu, Seoul 07301, Korea

Tel: +82-2-2678-0001

Fax: +82-2-2678-2175

E-mail: hjoonyoo@gmail.com

*Chair of the Semicentennial

Committee of the Korean Geriatrics

Society

Received: November 1, 2018

Revised: November 5, 2018

Accepted: November 5, 2018
The Korean Geriatrics Society was founded on October 3, 1968. Over the 50 years since then, the Society has incessantly strived to stay attuned to the aging society and to achieve an increasingly greater research impact in the field of gerontology and geriatric medicine. The Society has passed through periods of preparation for a leap forward, followed by rapid growth, expansion, and maturity. As a result, the Society has gained a firm foothold at home and abroad as a leading research society for both qualitative and quantitative achievements in geriatric medicine. At this juncture, with an ultra-aging society being just around the corner, we are celebrating its 50th anniversary and anticipating our second half-century with great enthusiasm about our mission and role as a leading geriatric research organization. (Ann Geriatr Med Res 2018;22:159-166)

Key Words: Korean Geriatrics Society, 50 Years, Semicentennial, History

\section{INTRODUCTION}

Modern geriatric medicine was established and has been developing since Dr. Nascher proposed the term "geriatrics" in $1909 .^{1-3)}$ The American Geriatrics Society was founded on June 11, 1942 at Hotel Brighton in Atlanta by Malford W. Thewlis. ${ }^{4,5}$ The British Geriatrics Society was founded in $1947^{6,7)}$ The International Association of Gerontological Societies, the predecessor of the current International Association of Gerontology and Geriatrics (IAGG), was founded in 1950 when it hosted the First World Congress. ${ }^{8)}$ The Japan Geriatrics Society and the Japan Gerontological Society were inaugurated in 1959.9) This global trend of geriatrics raised awareness among some medical scientists in Korea regarding the need for an organization specializing in geriatrics. Their concerted efforts led to the foundation of the Korean Geriatrics Society in 1968; it was launched with 53 founding members. Now, after 50 years, it boasts over 7,000 members. Unsurprisingly, this quantitative expansion has been paralleled by qualitative growth. I will look back on these five decades of the Korean Geriatrics Society in its 5 different stages of development, namely, foundation, preparation for a leap forward, revival, expansion, and maturity. ${ }^{10,11)}$

\section{FOUNDATION}

A group of initiators led by Soon Gyu Seo and Deok Ho Lee started a research society in 1966, but did not achieve any concrete milestones. A second launch was attempted in the summer of 1968 (Fig. 1). Sung Ho Lee, Deok Ho Lee, Soon Gyu Seo, Byung Yoon Lee, Yong Pal Ahn, and Hak Joong Kim were among the initial members. Concerns about the increasing number of geriatric conditions and diseases around that time prompted the decision to launch the Korean Geriatrics Society (hereafter referred to as the "Society"), and the inaugural meeting was held in the Faculty Conference Room of Seoul National University College of Medicine on October 3, 1968 with 53 founding members. Sung Ho Lee was elected the first President, and Soon Gyu Seo and Deok Ho Lee, the Vice Presidents. A year later, its first Meeting was held on November 22, 1969 (Fig. 2), ${ }^{10}$ followed by Annual Meetings thereafter. After the 5th Symposium in 1973, however, the Society's activities diminished to small-group seminars. However, the Society was restructured with a special conference and general assembly on November 28, 1980. Soon Gyu Seo was elected as the President in the general assembly, and on January 17, 1981, new board members were constituted in a roundtable meeting of the Society. Since then, the Society has held semiannual meetings and contributed considerably to the development of research and clinical 


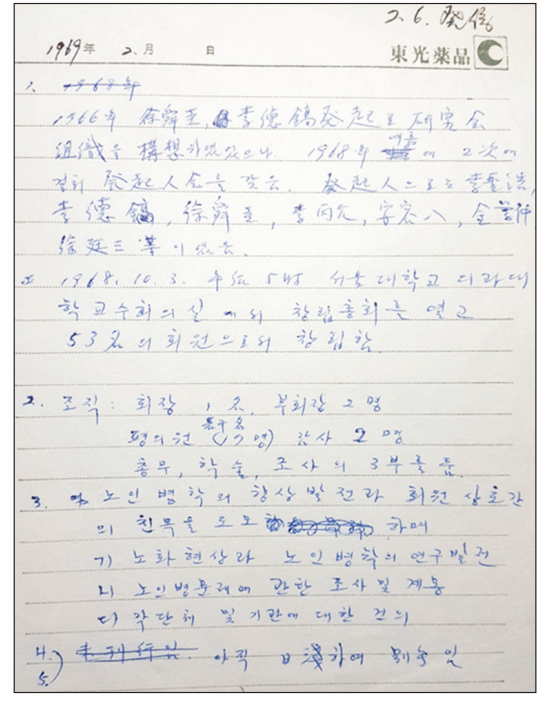

Fig. 1. A handwritten meeting note from around the time the Korean Geriatrics Society was founded (February 1969). The dispatch date is shown in the top right corner (February 6), but the addressee is unknown. The first item of the note reads: Soon Gyu Seo and Deok Ho Lee came up with the idea to organize a research society in 1966, but it was in the summer of 1968 that 2 founders' meetings were held. Sung Ho Lee, Deok Ho Lee, Soon Gyu Seo, Byung Yoon Lee, Yong Pal Ahn, Hak Joong Kim, and Jung Sam Seo were among the founding members. This note documents that Soon Gyu Seo and Deok Ho Lee laid the cornerstone for the foundation of the Society. The note-taker is unknown, but is assumed to be one of the founding members.

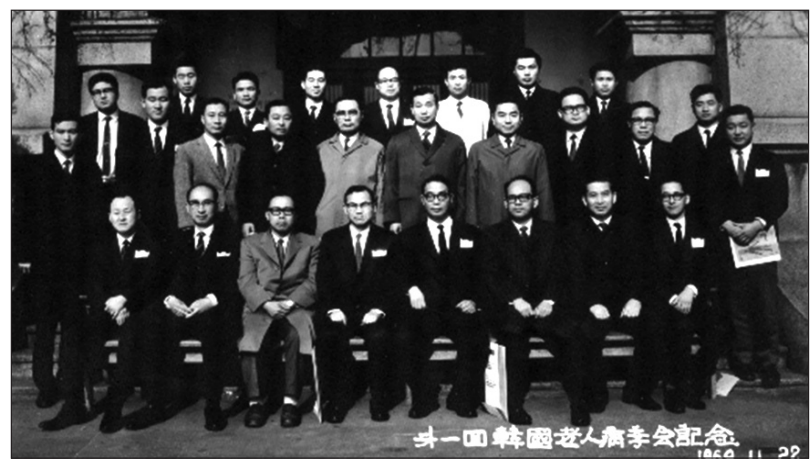

Fig. 2. A commemorative picture of the first symposium of the Society held on November 22, 1969 (1 year after the foundation) in the Auditorium of Seoul National University Hospital (in front of the main building of Seoul National University College of Medicine; inscription in the bottom right corner of the picture: Commemoration of the First Symposium of the Korean Geriatrics Society).

practice in the field of geriatric medicine. Nonetheless, its external relations and cooperation efforts lagged behind other Society activities.

\section{PREPARATION FOR A LEAP FORWARD}

On January 14, 1994, the first executive committee meet-

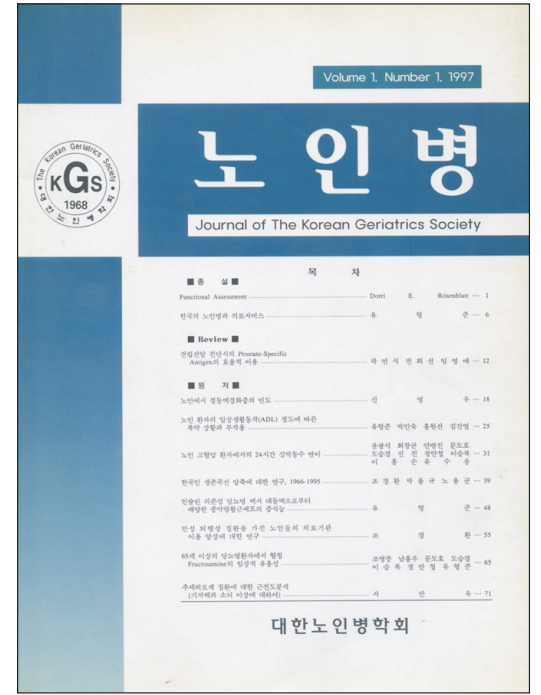

Fig. 3. The inaugural issue of The Journal of the Korean Geriatrics Society (1997).

ing was held with the initiative of some active members who recognized the urgent need for geriatric medicine and research. The members elected Keon Yeol Kim (Department of Internal Medicine, Danguk University School of Medicine) as the 6th President and Hyung Joon Yoo (Department of Internal Medicine, Hallym University College of Medicine) as General Secretary, thus paving the way for a leap forward. In an effort to refresh the conceptual definition of geriatrics and raise awareness of the need for geriatric care among clinicians, the Society refurbished its organizational structure by joining the Korean Academy of Medical Sciences as an official affiliate member on May 3, 1994. It also designed its semiannual meetings as platforms for in-depth symposiums and discussions about the general views and research trends in geriatric medicine. Along these lines, the key focus of the symposia and discussions at the 1994 annual meeting was on general considerations concerning geriatric diseases, and in 1995, intensive reviews and discussions were devoted to clinical issues more prevalent among older adults (especially, cardiovascular diseases). Such endeavors for this reconceptualization of geriatric medicine came to fruition, and from the 1996 annual meeting, participants started to present their original studies at the conference and symposia, an activity which had been suspended for a while, greatly enriching our conferences as an academic platform. In 1997, the Geriatric Research Committee and the Academic Committee were convened within the Society. Both committees held regular seminars every other month and contributed to promoting qualitative depth and quantitative expansion of research in geriatric medicine. Furthermore, moving away from irregularly publishing a journal, the Society launched the semiannual periodical, The Journal of the Korean Geriatrics Society (Fig. 3), publishing handpicked original research articles. Also in 1997, the Society 
decided to implement the certification system for certified geriatricians.

\section{REVIVAL}

In 1998, the Society began to offer the lecture series "Geriatric Workshop" to practitioners and planned to compile and publish the textbook "Geriatric Medicine." In addition, the Society became a member society of the Federation of Korean Gerontology Societies (members: Korean Geriatrics Society, Korea Gerontological Society, Korean Society for Gerontology, and Korean Association for Geriatric Psychiatry) as a society responsible for clinical medicine. Accordingly, the Society maintained interactive relationships with other member societies and played a pivotal role in hosting the 6th Asia/Oceania Regional Congress of Gerontology held in Seoul in June 1999.

A landmark event that deserves particular attention is President Hyung Joon Yoo's mediation between the Korean and Japanese Geriatrics Societies towards aca-demic exchanges, leveraging his personal contacts with Professor Ouchi of the Department of Geriatrics, Tokyo University Graduate School of Medicine and Professor Kita of the Department of Geriatrics, Kyoto University Faculty of Medicine, in an attempt to help the Society develop into an international organization. The Society seized the opportunity and appointed then Academic Di-rector Hong Soon Lee as the task force commander. Lee's negotiations with the Japanese counterparts led to the 1st "Joint Symposium between Korean Geriatrics Society and Japanese Geriatrics Society," which was held on May 13, 2000 in Garden View of Seoul National University Hospital Biomedical Research Institute under the theme "What is the necessity of geriatrics? What should we do?" (Fig. 4). It was the first regular joint academic event with a geriatric society of an-

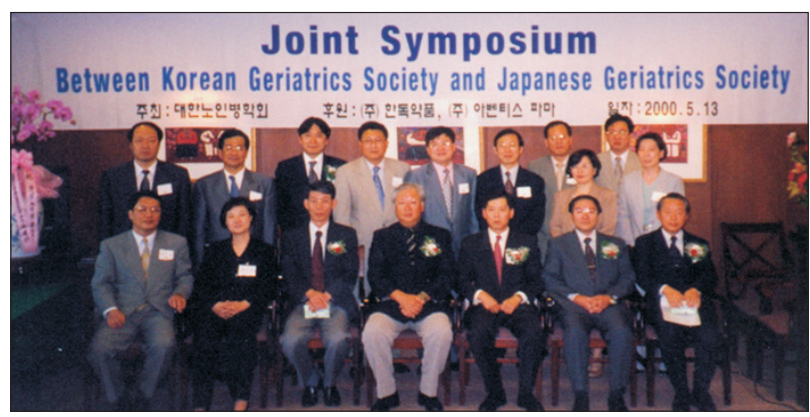

Fig. 4. The 1st "Joint Symposium between Korean Geriatrics Society and Japanese Geriatrics Society" hosted by the Society, held on May 13, 2000 in Seoul National University Clinical Research Institute Garden View (clockwise from the bottom-right: Nagoya School of Medicine, Tokyo School of Medicine, Young Soo Lee, Kyoto School of Medicine, Nagoya School of Medicine, In Soon Kwon, Hyung Joon Yoo, Hong Soon Lee, Cheol Ho Kim, (skipping one person) Hong Woo Nam, Yong Deuk Jeon, Kyung Wan Min, (skipping 1 person) Hyun Wook Baik, (skipping 1 person) Eun Joo Lee. other country. The speakers and their respective topics are as follows: Hyung Joon Yoo (Hallym University College of Medicine, Department of Internal Medicine), "What happens to geriatric patient care in Korea?"; Yasuyoshi Ouchi (Tokyo University Graduate School of Medicine) "Opinion from Japan about patient care"; Chul Ho Kim (Seoul National University College of Medicine, Department of Internal Medicine), "Opinion from Korea about education and research"; Professors Iguchi and Suzuki (Nagoya University Graduate School of Medicine, Department of Geriatrics), “Opinion from Japan about Education and Research." ${ }^{10,12)}$

\section{EXPANSION}

Notwithstanding the difficult situation associated with Korea's pharmaceutical policy reform, the "separation of prescribing and dispensing drugs" at that time, the Society successfully held the 25th Spring Symposium (June 24,2000 ) and the 4th Workshop (June 25, 2000) with 400 participants. In particular, at the 25th Spring Symposium, we celebrated the publication of the textbook "Geriatric Medicine" (Fig. 5), which was published in June 2000 following two and a half years' preparation by the compilation committee (chair: Hyung Joon Yoo), which convened in January 1998. Because of the rapid accumulation of clinical experiences with geriatric diseases and growing research interest, at that time, it was judged necessary to reflect new insights and knowledge in the textbook. In July 2004, the Society convened a compilation committee to work on the revision of "Geriatric Medicine." The work on the third edition began in 2013 and was published in May 2015 after 2 years of strenuous work. A total of 109 writers contributed to the third edition of the textbook, which demonstrates the enormous extent of academic progress and knowledge expansion in the field of geriatric

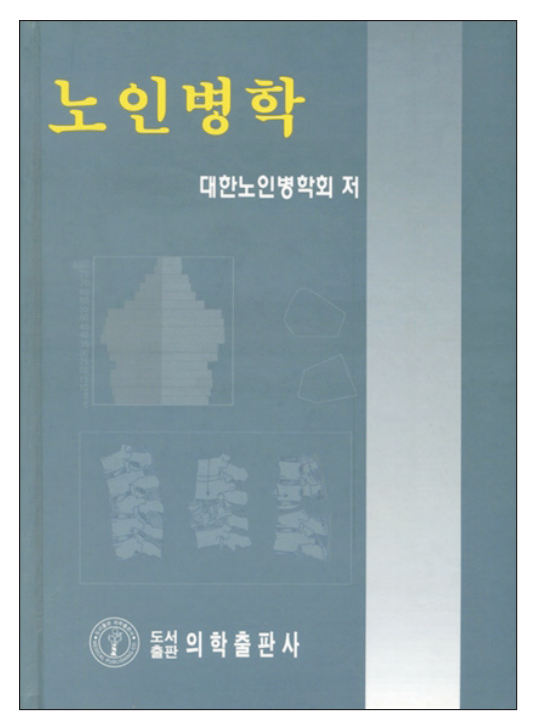

Fig. 5. The textbook "Geriatric Medicine” (1st edition, 2000). 
medicine during a short time.

On October 2, 2000, the first "Healthy Senior Citizen Contest" was held at the Seoul Veterans Hospital, which was an occasion for strengthening the standing of the medical research organizations in creating a healthy longevity society. In the following year, 2001, we accelerated the progress of the geriatrician certification system. On February 3, 2001, we administered the first examination for geriatrician certification and thereafter, had an exponential increase in membership. On the strength of this momentum, the Society gained status as a regular member of the Korean Academy of Medical Sciences on June 14, 2001.

In 2002, Hong Soon Lee was inaugurated as the first Chairperson since we decided to adopt the chairperson system in 2001, and the terms of the President and the Chairperson were adjusted to 1 year and 2 years, respectively. By this time, the membership had reached 3,200, and the Society ranked among the top 10 Korean research societies. The publication of the monograph "Vascular Aging" in Vascular Aging \& Related Disorders Research bespoke the stature of the Society at the apogee of its academic achievement. In particular, we created the "Academy Award" with the intent to encourage the research community to perform more gerontological research, and the first award ceremony was held during the 2003 Fall Symposium.

On June 5, 2004, the 33rd Spring Symposium was held at Daegu Inter Burgo Hotel, where we hosted a policy forum on the "reality and problems of the long-term care facilities." The 34th Symposium held at Lotte Hotel in Sogong-dong, Seoul on October 30, 2004 saw a record number of attendees comprising 1,349 members, certified geriatricians, residents, and other participants. The symposium program was filled with policy forums, special lectures, symposia, and presentations. In August, between the spring and fall symposia, the 4th examination for geriatrician certification was administered, increasing the number of certified geriatricians to 1,809 , and the number of Society members to 3,800. The year 2004 also saw the foundation of the Yeongnam Branch (president: Young Woo Shin), which became the starting point for establishing Society branches.

On June 18, 2005, the 35th Spring Symposium was held at Daegu Inter Burgo Hotel with 1200 participants. During the symposium, we celebrated the publication of the revised edition of the textbook "Geriatric Medicine." In July, The Journal of the Korean Geriatrics Society was indexed in KoreaMed after passing review by the Korean Association of Medical Journal Editors. The 36th Fall Annual Meeting (October 15, 2005) was held at the Grand Walkerhill, accompanied by the 3rd Joint Symposium between the Korean Geriatrics Society and the Japanese Geriatrics Society, in which the latest clinical findings in geriatric medicine and basic medical scientific papers were presented and discussed. This annual meeting also offered clinical geriatric nurses a special "geriatric nurse session," which attracted much attention, with 70 nurses participating in the session.

In September 2006, the Society stipulated the "Research Grant Award Rules of the Korean Geriatrics Society" to provide support for research projects that may contribute to the development of gerontology and to foster research efforts in the field of geriatric medicine.

On April 10, 2007, the Society moved its office from the office of the Director of Internal Medicine of the $\mathrm{Na}$ tional Medical Center to \#405 Samsung Parkville, 5 Euljiro, Jung-gu, Seoul. On September 8th and 9th, the Society participated in the Government-led "2007 Senior Expo" held at the KINTEX, Goyang, with the theme "Health Tips from the Best Doctors" and a symposium on the conditions for successful operation of a geriatric hospital. At the 7th Joint Symposium between the Korean Geriatrics Society and the Japanese Geriatrics Society, which was held concomitantly with the Fall Annual Meeting on November 17th, a joint research project on geriatric hospital quality assessment was on the agenda.

Celebrating the 40th anniversary of the Society in 2008, we hosted the 40th Anniversary International Conference and the 42nd annual meeting at the Grand Hilton Hotel, Seoul on November 22, 2010, and celebrated the publication of the Geriatric Glossary. Another remarkable event of 2010 was the appointment of the Chairperson Hyung Joon Yoo as the President of the Korean Association of Gerontology and Geriatrics in May, which led to the promotion of collaborations with related societies. Moreover, along with the growing capacities and activities of the Society, we started the "Korean Geriatric Medicine Research Foundation" for the purpose of enhancing the financial soundness necessary for the management of the Society, supporting and training geriatrics researchers, and promoting

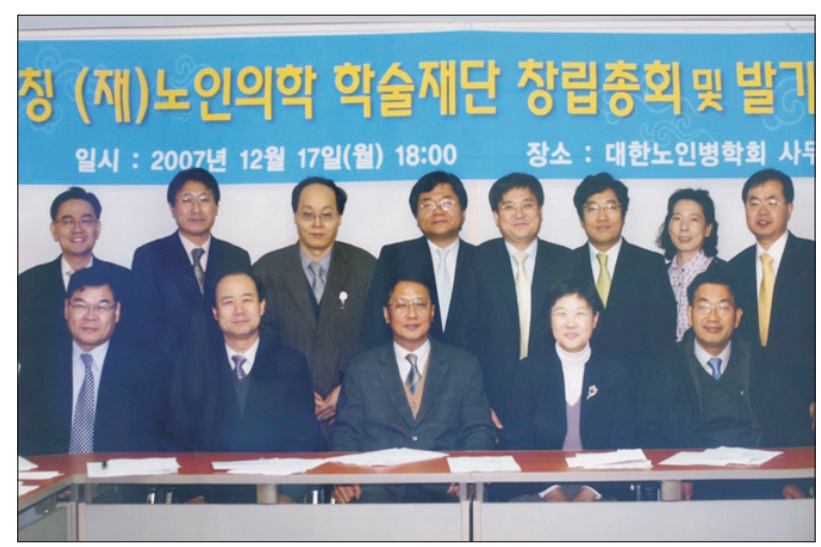

Fig. 6. Founders' Meeting of the Korean Geriatric Research Foundation (December 17, 2007) (clockwise from the bottomright: Hyun Rim Choi, In Soon Kwon, Hyung Joon Yoo (the first chairperson), Seok Hwan Shin, Min Ho Jeon, Hong Woo Nam, Soon Joo Wang, Dong Woo Lee, Yong Deuk Jeon, Bon Lee, Eun Joo Lee, and Hak Chul Jang. 
a public health project for geriatric disease prevention (Fig. 6). On July 1st, the "Research Society for Geriatric Surgery" was launched as an affiliated research group and the first meeting offered a policy seminar on the "strategies for establishing the functions of nursing facilities and hospitals" at the 2008 Senior and People with Disabilities Expo held at the KINTEX in Goyang, on July 1st.

In 2009, Jung Ae Lee was inaugurated as the 17th President. The website was fully refurbished, and its demonstration took place at the Gwangju Kimdaejung Convention Center during the 43rd Spring Annual Meeting (May 30). This Annual Meeting was the first one to be held in the Honam region. At the IAGG 2009 World Congress (19th) which took place in Paris from July 5-9, the Society attracted attention by holding a "KGS Symposium" on "Screening for Gastric Cancer in Oriental and Western Older Adults." The foundation of the Chungcheong Branch (president: Gang Seo Park) at Daejeon Eulji University Hospital on October 16 and Jeju Branch (president: Kyung Hoon Han) on November 7 empowered the Korean Geriatric Society to establish a nationwide regional network. On the other hand, the Society's The Journal of the Korean Geriatrics Society was selected as a candidate journal of the National Research Foundation of Korea on December 26,2009 . As a result, the papers published from the January 2009 issue onwards have been retroactively rated as high in assessments for research performance.

\section{MATURITY}

In 2010, we began to seek to take systematic action at the level of academic society by appointing three policy boards (health insurance, health policy, and long-term care) for geriatric issues and launching a "Policy Committee" chaired by the Vice President Seok Hwan Shin. In accordance, the Spring Annual Meeting focused on the topic "reality and trends in geriatric health care policy," and the Fall Annual Meeting was dedicated to policy discussion on "adequacy assessment of long-term care facilities." Additionally, to celebrate the International Day of Older Persons (October 1), we had a commemorative seminar concerning the "efficient management of geriatric health care" at the Korea Press Center on September 28. In March 2010, the Society Secretariat moved from Samsung Parkville in Eulji-ro to \#2005 Anam Tower in Yeoksamdong, Gangnam-gu.

On May 28 and 29, 2011, the Korean Geriatric Functional Assessment was presented at the 47th Spring Symposium at Asan Medical Center, to expand functional assessments among older outpatients. On September 15, the Society Secretariat moved from Anam Tower in Yeoksamdong to \#401 Hyundae Venturetel in Yeoksam-dong. The Society launched a health portal for the general public where it provided people with basic information about geriatric conditions and diseases and installed the menu "Find a Hospital in the Neighborhood," showing that the Society cares for people's wellbeing as a society and seeks to improve their lives.

On June 28, 2012, the 12th Joint Symposium between the Korean Geriatrics Society and the Japanese Geriatrics Society was held in Tokyo. At the 50th Fall Symposium (December 8) held at Asan Medical Center, a policy forum on "direction for geriatric professionals in the aging era" attracted keen attention. From the 50th Fall Symposium (2012) onwards, the Society decided to levy a registration fee for senior members (aged >65 years), which had been waived at a reduced rate (50\%), in consideration of the Society's finances.

The 20th IAFF World Congress (2013) was successfully held at COEX Seoul from June 23 to 27, 2013, as a member of the Korean Association of Gerontology and Geriatrics.

At the 2014 Spring Annual Meeting (53rd) and Fall Annual Meeting (54th), the Society opened policy forums on "status of and strategy for geriatric health promotion" and "status of and direction for geriatric nursing hospitals," respectively, focusing on practical policy areas to promote the quality of life of older adults. The Society also placed considerable effort into promoting activities of its affiliated research societies and local branches. On September 16, the Society entered into a memorandum of understanding with the National Health Insurance Service for joint research on the risk factors and management strategies for geriatric syndromes. On October 17, we held a policy seminar on the "status of and direction for long-term geriatric care hospitals" as an ad hoc seminar, for diagnosing the situations and problems associated with improving the conditions of long-term care hospitals, with safety problems emerging as a serious social issue in the aftermath of the fire outbreak at Hyosarang Hospital in Jangsung, Jeonnam in May 2014.

In 2015, we celebrated the publication of the third edition of the textbook "Geriatric Medicine" during the 55th Spring Annual Meeting on May 30. The revised textbook was to replace the 10-year-old second edition released. Chul Ho Kim led the compilation team as the editor-inchief and completely revised the older version, incorporating the academic changes and data accumulated over the decade. In the field of research, the "Brain Health Research Society" was officially launched in January, and the "Geriatric Palliative Care Research Society" was launched in May, marking the pinnacle of specific research groups to meet research needs arising from diversifying patterns of geriatric conditions and diseases. The year 2015 also saw the launch of the English version website and The Journal of the Korean Geriatrics Society being indexed in Korea Citation Index, the journal database of the National Research Foundation of Korea. ${ }^{13)}$

At the 57th Spring Annual Meeting held at Chungnam National University Hospital on May 28, 2016, we celebrated the publication of "Case of Geriatric Syndromes," which was authored by the "Geriatric Syndromes Research 
Society" (lead author: Hyung Joon Yoo) to enable readers learn the basic and general aspects of geriatric syndromes. A landmark event of particular im-portance was the internationalization of The Journal of the Korean Geriatrics Society that occurred by changing its name to Annals of Geriatric Medicine and Research (AGMR) and the language from Korean to English. The inaugural issue of the AGMR was released in September (Fig. 7). In response to the accelerating population aging, the Society mounted a health promotion campaign "Living Healthy to 100 Years" from September to November in synchrony with the International Day of Older Persons (October 1); this campaign attracted substantial public and media attention.

The 59th Spring Annual Meeting was held at Hotel Maison Glad in Jeju on May 27, 2017. On the next day, the traditional Korea-Japan Symposium was extended to a tripartite symposium with the with the inclusion of the Taiwan Association of Gerontology and Geriatrics. The epidemiology and assessment tools of fall in older adults were discussed during this tripartite symposium. The Korea-Japan-Taiwan Symposium was held in 2018 (June 14) in Tokyo, where the participants (one moderator and 2 speakers from each of the 3 member countries) presented papers and jointly discussed the topic "End-of-Life Care." The Society instituted two more awards, "Distinguished Academic Award" and "Young Researcher Award," and began to present them at the next Spring Annual Meeting. The first laureates of the Distinguished Academic Award and the Young Researcher Award were Chang-Won Won (Department of Family Medicine, Kyunghee University Hospital) and Kyung Min Kim (Division of Endocrinology, Department of Internal Medicine, Seoul National University Bundang Hospital), respectively. In 2018, Hak Chul Jang (Division of Endocrinology, Department of Internal Medicine, Seoul National University Bundang Hospital) won the Second Distinguished Academic Award, Ji Eun Lee (Department of Family Medicine, Bundang Medical Center) the Second Young Researcher Award, and the Spe-

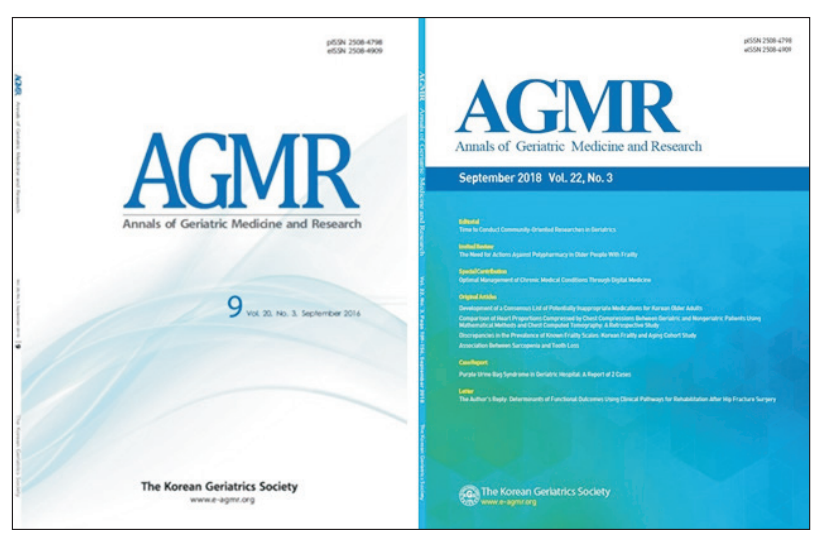

Fig. 7. Annals of Geriatric Medicine and Research (AGMR), the English journal of the Society: change of the journal title from The Journal of the Korean Geriatrics Society to AGMR, acronym of the in September 2016, with a change of cover design in 2018. cial Academy Grand Award on the occasion of the 50th anniversary went to Hyung Joon Yoo (Department of Internal Medicine, CM Hospital).

With the momentum gained from the large steps forward made in the internationalization of academic exchanges, the Society hosted the 3rd Asian Conference for Frailty and Sarcopenia Symposium (Fig. 8) at Healthcare Innovation Park, Seoul National University Bundang Hospital on October 27-28, 2018 in tandem with the 60th Fall Annual Meeting (October 28-29). Six world-renowned scholars in the field of frailty and sarcopenia delivered keynote speeches, and 14 sessions of the international expert symposium were held, filling the venue platforms with exchanges among researchers from around the world.

The 61st Spring Annual Meeting held at the Py-eongchang Alpensia Convention Center on May 19-20, 2018 hosted a forum designed to illuminate the medical influence of the Life-sustaining Treatment Decision making Act, which came into effect in February 2018, and the role of physicians. This forum attracted much attention; various topics related to the overall situation and developing directions of geriatric medicine were assigned to 13 different sessions for sharing relevant knowledge and information. In February, the Society had an exciting moment watching its journal AGMR indexed in Emerging Sources Citation Index (ESCI). An ESCI journal may be upgraded to SCIE (Science Citation Index Expanded) depending on the citation assessment within 2 years following its entry into ESCI. Therefore, this could be another stepping stone towards the globalization of the academic work pursued by the Society.

In the foregoing section, I have provided a concise history of the Korean Geriatrics Society spanning 50 years of its pioneering efforts to establish an academic framework for geriatric medicine; this framework has converged with our researchers' passionate and enthusiastic work, and we have strived to create an environment enabling comprehensive management of geriatric healthcare. In the meantime, our country is facing the challenges of an aged society, with those aged 65 years and over now compris-

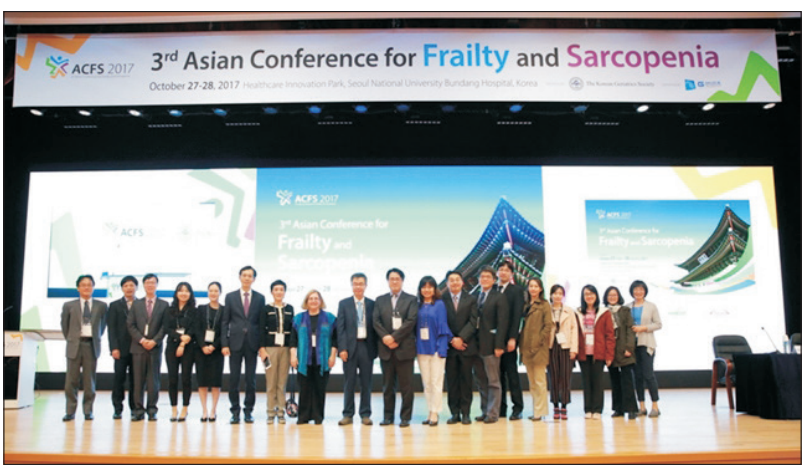

Fig. 8. The 3rd Asian Conference for Frailty and Sarcopenia Symposium held on October 28-29, 2017 in tandem with the 60th Fall Symposium. 
ing $15 \%$ of the population, and this fraction of the population is increasingly accelerating. With the super-aged era just around the corner, I allow myself to take an optimistic view, thanks to the work done by our older generation who founded the Korean Geriatrics Society and who wisely looked ahead half a century ago. These founders handed down a mature and prestigious academic society, so that we can continue the work with confidence based on the academic and clinical frameworks the Society has built thus far. Now it is our turn, as geriatric professionals of this generation, to look ahead another 50 years, to plan and prepare for human life spanning 120 years and to reflect on our roles and duties in the decades to come. ${ }^{14-18)}$ The primary tasks are training skilled and highly specialized geriatricians on the one hand, and building systems and environments favorable for geriatric research and clinical advancement on the other.

For this purpose, we must establish various guidelines for the establishment of evidence-based geriatric care; spur the development of geriatrics curricular modules for students, residents, and general practitioners; and continue to present reasonable alternatives in the field of medical policies so that high-quality geriatric care may be provided. At the same time, it is an imperative task to improve global competitiveness by strengthening exchanges and cooperation with associations and international conferences to further elevate the Society's status as an academic research group. To accomplish all these things smoothly, it is expected that all geriatric medicine-related scientists will do their utmost in playing their respective roles within our Society.

Additionally and simultaneously, we should respond to the needs of our time and endeavor to boost our global competitiveness by strengthening exchanges and cooperation with other societies and international counterparts to further elevate our position as an academic research organization. To carry out these tasks and achieve these goals efficiently, we should be committed to the mission of all geriatric professionals and to our roles and duties as the constituents of our Society, converging our knowledge and skills towards the center of our Society.

\section{CONCLUSION}

At this juncture, looking back on the past 50 years of our Society, with the super-aged era right at the doorstep, we are sincerely thankful to the researchers of the previous generation for their wisdom in looking forward and creating the Korean Geriatrics Society, leaving us with a firm academic framework to continue with the work on which they embarked 50 years ago. Over the past five decades, our Society has been able to build academic and clinical frameworks of gerontology and geriatric medicine with the concerted efforts of all members, and it has consistently played a leading role in creating conditions for the comprehensive management of geriatric healthcare.
Now it is time for us to reflect on the role of the Society afresh, looking ahead to a centennial history of the Society and the centenarian longevity of humans. The more the reflection is true to the principle that "an academic research organization can grow and develop only if it excels in academicity, activities, communication, and comradeship," the more valuable its fruits will be. In this regard, we are lucky: the past 5 decades of our society have abounded in academicity, activities, communication, and comradeship. Therefore, the Korean Geriatrics Society has the right to wish for an excellent centennial history and centenarian longevity, and we have obligations to fulfill that hope.

\section{CONFLICTS OF INTEREST DISCLOSURES}

The author claims no conflicts of interest.

\section{ACKNOWLEDGMENTS}

I would like to extend my sincere gratitude to the semicentennial project team and staff of the Secretariat, who assisted me with data collection.

\section{REFERENCES}

1. Nascher IL. A history of geriatrics. Medical Rev 1926;32:281-4.

2. Nascher IL. Geriatrics. NY Med J 1909;90:358-9.

3. Clarfield AM. Dr. Ignatz Nascher and the birth of geriatrics. CMAJ 1990;143:944-5.

4. Morley JE. A brief history of geriatrics. J Gerontol A Biol Sci Med Sci 2004;59:1132-52.

5. Grimley Evans J. Geriatric medicine: a brief history. BMJ 1997;315:1075-7.

6. Matthews DA. Dr. Marjory Warren and the origin of British geriatrics. J Am Geriatr Soc 1984;32:253-8.

7. Kong TK. Dr. Marjory Warren: the mother of geriatrics. J Hong Kong Geriatr Soc 2000;10:102-5.

8. Yoo HJ. Geriatric medicine: a brief history. J Korean Geriatr Soc 2014;18:1-6.

9. University of Tokyo, Department of Geriatric Medicine. 50th Anniversary Commemorative Book. Tokyo: University of Tokyo; 2013.

10. Yoo HJ. History of Korean geriatrics society. J Korean Geriatr Soc 1997;1:1-4.

11. Yoo HJ. The past and present of Korean geriatric medicine. J Korean Geriatr Soc 2005;9(S3):2-4.

12. The Korean Geriatrics Society [Internet]. Seoul: The Korean Geriatrics Society; c2014 [cited 2018 Oct 25]. Available from: http:// www.geriatrics.or.kr/.

13. Korean Geriatrics Society. 50 Years of Korean Geriatrics Society. Ann Geriatr Med Res 2018;22(Suppl 4):107-8.

14. Yoo HJ. The present and future of geriatric education in Korea. J Korean Intern Med Assoc 2010;79(S2):513-6.

15. Choi H. Present and future of Korean geriatrics. J Korean Geriatr Soc 2011;15:71-9. 
16. Weiss BD, Fain MJ. Geriatric education for the physicians of tomorrow. Arch Gerontol Geriatr 2009;49 Suppl 2:S17-20.

17. Yoshikawa TT. Future direction of geriatrics: "gerogeriatrics". J Am Geriatr Soc 2012;60:632-4.

18. Yoo HJ. The medicine for the aged society: the answer in science.
Chapter 2 Medical Care Measures, Korea Academy of Medical Science - Korea Science and Technology Academy - Korea Academy of Engineering College of Science Proposal Issue Paper 2017-06. Seoul: Kyungsung Munhwa Co.; 2018(January):26-35. 